\title{
Analysis of Rifampicin in Dried Blood Spot of Tuberculosis Patients for Therapeutic Drug Monitoring using High Performance Liquid Chromatography
}

\author{
Yahdiana Harahap ${ }^{1}$, Fauzan Alkindy ${ }^{1}$, Ghina Ashiila ${ }^{1}$, Rahmayanti ${ }^{2}$ \\ 'Faculty of Pharmacy, Universitas Indonesia, UI Depok Campus, Depok, 16424, INDONESIA. \\ ²Bekasi General Hospital, Bekasi, INDONESIA.
}

\begin{abstract}
Objective: This research aimed to determine rifampicin in dried blood spot of tuberculosis patients using cilostazol as internal standard by high performance liquid chromatography for supporting therapeutic drug monitoring. Method: Analytes were extracted by protein precipitation using methanolacetonitril (4:1). The analytical separation was performed on C-8 column (Waters, Sun fire ${ }^{\mathrm{TM}} 5 \mu \mathrm{m} ; 250 \times 4.6 \mathrm{~mm}$ ) with column temperature of $40^{\circ} \mathrm{C}$. The mobile phase used was acetonitrile - methanol - ammnonium acetate buffer $\mathrm{pH} 4.5(40: 30: 30 \% \mathrm{v} / \mathrm{v})$ with a flow rate of $0.5 \mathrm{~mL} / \mathrm{min}$; and detected at $261 \mathrm{~nm}$. Results: The method had a chromatographic run time of $16 \mathrm{~min}$ and linear calibration curve over the range of $1-30 \mu \mathrm{g} / \mathrm{mL}$ with a correlation coefficient ( $r$ ) of 0.998 . The result of the analysis of rifampicin in 18 tuberculosis patients showed that the measured value of rifampicin was in the range of 1.26 to $18.33 \mu \mathrm{g} / \mathrm{ml}$. Conclusion: Based on the result, the concentration
\end{abstract}

of rifampicin in patients were varied. There were 7 of 18 patients which had concentration in therapeutic range, showing that the treatment is appropriate, while 11 of 18 patients had concentration below the therapeutic range showing that dose adjustment is needed.

Key words: Rifampicin, HPLC, Tuberculosis, Validation, Dried blood spot.

Correspondence

Yahdiana Harahap, Faculty of Pharmacy, Universitas Indonesia, UI Depok Campus, Depok-16424, INDONESIA.

Phone: +62818222192

Email: yahdiana03@yahoo.com

DOI: 10.5530/jyp.2018.10.12

\section{INTRODUCTION}

Tuberculosis is an infection disease caused by Mycobacterium tuberculosis. The disease generally attacks lung and is transmitted through coughing and sneezing. The appearing symptoms are coughing with blood, chest pain, sweating at night, fever for more than 1 month, weight loss, and anorexia. ${ }^{1}$ World Health Organization, estimated that 8.8 million people were infected with TB in $2010 .^{2}$ Indonesia is one of the countries with high risk of TB in Southeast Asia. Among 500,000 cases occurs every year, 175,000 of humans had died. Antituberculosis first line drugs are rifampicin, pyrazinamide, ethambutol, and isoniazid. Mycobacteria caused by TB can colonize in the cell and develop the ability of resistance to fight antituberculosis and certain drugs. To prevent that condition, treatment of TB must consist of 2 more drugs to prevent a resistance and reduce its side effect. ${ }^{3}$ Mycobacteria response to drugs is very slow therefore treatment should also lasts more than 2 months until one year. Combination of first line antituberculosis is present in the form of fixed dose combination. ${ }^{4}$

Rifampicin is an antibiotic from macrolide group, which blocks the initial conformation of RNA chain of the bacteria and inhibits the growth of positive $g$ and negative $g$ bacteria. Rifampicin is absorbed rapidly in the GIT, distributed to whole body in effective concentration to many organs and body fluids, including cerebrospinal fluids. ${ }^{5}$ Rifampicin is an antibiotic type which can cause a drug resistance. The resistance organism can hold drug activity, so the standard of treatment is not effective, and the infection will be persistent and spread. Therapeutic range of rifampicin is $8-24 \mu \mathrm{g} / \mathrm{ml}$ and a dosage increace is recommended if the concentration of rifampicin is less than $6 \mu \mathrm{g} / \mathrm{ml} .{ }^{5}$

Therapeutic drug monitoring (TDM) is a part of clinical practice for measuring specific drugs at designated intervals to maintain a constant concentration in a patient's bloodstream, thereby optimizing individual dosage regiments. To know the effectiveness of a treatment, there should be determination of drug concentration around maximum concentration and elimination phase. ${ }^{6,78}$ Therapeutic effect of rifampicin was determined with drugs concentration in blood.

Biosampling method with dried blood spot and absorb paper had some advantages such as less invasive, only small volume needed, a relatively stable analyte, easy in distribution and storage, does not need a phlebotomist, reduce the risk of infection and cost-effective. ${ }^{9}$ To provide a reliable therapeutic drug monitrong method, rifampicin was analyzed in dried blood spot tuberculosis patients, who consume rifampicin and isoniazid in fixed dose combination at Bekasi general hospital. This research had accepted an ethical clearance from ethical committee at medical faculty Universitas Indonesia No 1102 UN2/F1/ETIK/2016.

\section{MATERIALS AND METHODS}

\section{Chemical and Reagents}

Rifampicin (U.S. Pharmacopeia, Rockville, U.S.), isoniazid (Zhejiang Jiangbei Pharmaceutical Co. Ltd, Taizhou, China), cilostazole as an internal standard (Assia Chemical Industries Ltd, Beer-Sheva, Israel), HPLC grade acetonitrile, HPLC grade methanol, ammonium acetate, and sodium dihydrogen phosphate (Merck), aquabidest and ascorbic acid from Brataco, Perkin Elmer 226 as the DBS card (Perkin Elmer, Massachusetts, U.S.), and whole blood from Indonesian Red Cross.

\section{Instruments}

High Performance Liquid Chromatography (Shimadzu, LC-20AD) equipped with pump, degasser (Shimadzu, DGU-20A $_{5}$ ), C-18 (Waters, 
Sunfire ${ }^{\mathrm{TM}} 5 \mu \mathrm{m} ; 250 \times 4.6 \mathrm{~mm}$ ), C-8 (Waters, Sunfire ${ }^{\mathrm{TM}} 5 \mu \mathrm{m} ; 250 \times 4.6 \mathrm{~mm}$ ), UV-Vis detector (Shimadzu, SPD-20A), column oven (Shimadzu, CTO10AS vp), autosampler (Shimadzu, SIL-20A), and data processor (Lab Solutions), spectrophotometer UV (Jasco), evaporator (Turbo Vap LV), ultrasonicator (Elmasonic), pH meter (EUTECH), vortex (Maxi Mix II), centrifugator (Digisystem), microcentrifugator (Spectrafuge 16M), micropipette Eppendorf (Soccorex).

\section{Chromatographic Condition}

This study was conducted using C-8, $5 \mu \mathrm{m}, 250 \mathrm{x} 4.6 \mathrm{~mm}$ by HPLC. The mobile phase consisted of $50 \mathrm{mM}$ ammonium acetate buffer, $\mathrm{pH}$ 4.5 - acetonitrile - methanol (40:30:30) with an isocratic elution. Injection volume was $20 \mu \mathrm{l}$. Detection was carried out at $261 \mathrm{~nm}$, the column temperature was $40^{\circ} \mathrm{C}$, and the flow rate was $0.5 \mathrm{ml} / \mathrm{min}$.

\section{Preparation of Standard Solution}

$10.0 \mathrm{mg}$ rifampicin and $5.0 \mathrm{mg}$ ascorbic acid was weighed then dissolved in the $50 \%$ methanol in $10 \mathrm{~mL}$ volumetric flask to obtain $1.0 \mathrm{mg} / \mathrm{mL}$ (1000 ppm) concentration. A $10.0 \mathrm{mg}$ cilostazole was weighed and was dissolved with $50 \%$ methanol in $10.0 \mathrm{~mL}$ volumetric flask to obtain 1.0 $\mathrm{mg} / \mathrm{mL}$ (1000 ppm) concentration. The dilution was conducted to obtain solutions in certain concentrations.

\section{Preparation of Mobile Phase}

Ammonium acetate for $1.927 \mathrm{~g}$ in $500 \mathrm{~mL}$ water, then orthophosphoric acid was added to make a $\mathrm{pH}$ value of 4.5 . The solution was mixed with acetonitrile and methanol to obtain acetonitrile-methanol-ammonium acetate buffer mixtures in 30:30:40 ratio.

\section{Sample Preparations}

A $1000 \mu \mathrm{L}$ whole blood which contain $1 \mu \mathrm{g} / \mathrm{mL}$ rifampicin were mixed with $50 \mu \mathrm{l}$ cilostazol as internal standard with concentration of $10 \mu \mathrm{g} /$ $\mathrm{mL}$. The solution was added with $1 \mathrm{~mL}$ acetonitrile and methanol (4:1) then vortex mixed for 2 minutes. The tube was then centrifuged for 15 min at $10.000 \mathrm{rpm}$. Organic phase was transferred to another tube and evaporated with Nitrogen gas for 20 minutes at $35^{\circ} \mathrm{C}$. The residue was then reconstituted with $200 \mu \mathrm{L}$ mobile phase. The aliquot was injected into the HPLC system.

\section{Method Validation of Rifampicin in Dried Blood Spot}

In this study the method validation refers to EMEA guideline for bioanalytical method validation..$^{10}$ Full validation of rifampicin analytical method in dried blood spot was conducted in term of parameters LLOQ, selectivity, accuracy, precision, and recovery, carry over, stability parameters, linear calibration curve, and dilution integrity.

\section{RESULTS}

\section{Method Validation of Rifampicin in Dried Blood Spot Selectivity}

Selectivity test was conducted in the blank DBS and LLOQ concentrations were obtained using plasma from six different sources. The study results showed no interferences peak in the retention time of the analyte and the internal standard.

\section{Carry Over}

The study showed no carry over effect in the blank DBS after injecting the highest concentration (ULOQ) of rifampicin. The carry over percentage still meets the requirements for analyte $(<20 \%)$ and IS $(<5 \%)$.

\section{Calibration Curve and LLOQ}

Calibration curve was linear with the correlation coefficient $(r>0.9980)$ in concentration range from 1.0 to $30 \mu \mathrm{g} / \mathrm{mL}$. LLOQ concentration of rifampicin was $1.0 \mu \mathrm{g} / \mathrm{mL}$ with the $\mathrm{CV}$ value of $6.22 \%$ and \% diff range between -0.92 to $15.68 \%$.

\section{Accuracy, Precision, and Recovery}

Accuracy and precision were conducted in within run and between run on 4 different concentrations, such as LLOQ, QCL, $\mathrm{QCM}$, and QCH. The accuracy and precision results of the within-run and between-run are shown in Table 2 . The recovery was conducted to compare the analyte peak respond in the DBS sample with the standard solution. The results of within-run and between-run precision and accuracy of rifampicin were less than $15 \%$ for CV and $20 \%$ for bias. The bias in within-run and between-run accuracy was $14.38 \%$ to $1.10 \%$ and $7.76 \%$ to $11.24 \%$.

\section{Dilution Integrity}

Dilution integrity was conducted to determine the accuracy, precision, and reliability of the dilution in bioanalytical process. If the in vivo rifampicin assay in the biologic matrix obtained more than the highest requirement in $30 \mu \mathrm{g} / \mathrm{mL}$, a dilution process should be conducted to provide a desirable calibration curve range.

\section{Stability}

The storage stability of rifampicin in DBS paper was evaluated to determine whether degradation occurred during long-term storage. Stability was determined by analyzing QC sample stored at room temperature over a period of 40 days. The data indicated that rifampicin was stable at room temperature for at least 40 days with bias of $12.54 \%$ and $14.76 \%$ on two concentration levels (QCL and QCH) respectively.

\section{Sampling Process on Tuberculosis Patients}

This study was approved (no: 1102 UN2/F1/ETIK/2016) by the Ethics Committee of Faculty of Medicine, Universities Indonesia. Prior to the study, the patients had signed the informed consent. The samples were dried blood spot of 18 tuberculosis patients who received rifampicin containing isoniazid in fixed dose combination in their anti-tuberculosis regiment. The received dosage was $300-600 \mathrm{mg} / \mathrm{m}^{2}$ of rifampicin. The patients fulfill the inclusion criteria such as:

a. patients of Bekasi General Hospital

b. receives rifampicin in fixed dosed combination with isoniazid

c. patient's age is 18-50 years old during the blood collection

d. patient is willing to take part in the research and sign the informed consent

Blood sample from patients as much as $100 \mu \mathrm{l}$ were collected at $2 \mathrm{~h}$ and $6 \mathrm{~h}$ after administration of rifampicin, the blood was spotted on the DBS paper and was dried for $3 \mathrm{~h}$. Then DBS paper was inserted to a zip lock bag and stored at room temperature until analysis was conducted.

\section{Analysis of Study Sample}

The rifampicin level was found on 18 patients sample with the lowest level of $3.7 \mu \mathrm{g} / \mathrm{ml}$ on patient SN04 and the highest level of $18.33 \mu \mathrm{g} / \mathrm{ml}$ on patient SN14 at $2 \mathrm{~h}$ after administration of rifampicin. Blood sampling $6 \mathrm{~h}$ after administration of rifampicinin showed the lowest level of rifampicin which was $1.26 \mu \mathrm{g} / \mathrm{ml}$ on patient SN08 and the highest level of rifampicin which was $15.15 \mu \mathrm{g} / \mathrm{ml}$ on patient SN14. The average level of rifampicin at $2 \mathrm{~h}$ after administration of rifampicin was $9.01 \mu \mathrm{g} / \mathrm{ml}$ and the average of rifampicin after $6 \mathrm{~h}$ after administration of rifampicin was $7.01 \mu \mathrm{g} / \mathrm{ml}$.

\section{DISCUSSION}

The results of this research were in accordance to the previous research which showed that blood sampling $2 \mathrm{~h}$ after administration of rifampicin 
shown the rifampicin at maximum concentration and blood sampling $6 \mathrm{~h}$ after administration of rifampicin shown the rifampicin at elimination phase. ${ }^{11}$ Meanwhile, Unsalan et al reported a different result showing that maximum concentration of rifampicin was seen at $3 \mathrm{~h}$ after administration of rifampicin and therapeutic range of rifampicin is $8-24 \mu \mathrm{g} / \mathrm{ml} .{ }^{12}$

\begin{tabular}{lcccc}
$\begin{array}{c}\text { Table 1: Table of selectivity test. } \\
\begin{array}{c}\text { concentration } \\
(\mu \mathrm{g} / \mathrm{mL})\end{array}\end{array}$ & & & & \\
\hline & WB & RIF & Blanko & \\
& A & 2901 & 114 & 3.93 \\
& & 3083 & 138 & 4.48 \\
& B & 2756 & 129 & 4,68 \\
1.00 & & 2400 & 141 & 5.88 \\
& C & 2186 & 268 & 12.26 \\
& & 2575 & 251 & 9.75 \\
& D & 2821 & 376 & 13.33 \\
& & 294 & 368 & 11.03 \\
& E & 2763 & 129 & 5,20 \\
& & 2686 & 289 & 4.67 \\
& F & 2313 & 291 & 10.76 \\
& & & & 12.58 \\
\hline
\end{tabular}

The analysis result of 18 patients tuberculosis showed rifampicin at maximum concentration in 11 samples were in therapeutic range at $2 \mathrm{~h}$ after administration. At $6 \mathrm{~h}$ after administration of rifampicin, 8 samples had concentration in therapeutic range, while 7 patients had concentration in therapeutic range after $2 \mathrm{~h}$ and $6 \mathrm{~h}$ after administration of rifampicin. It shows that the treatment is appropriate, and rifampicin is effective. Meanwhile, 6 patients did not meet the therapeutic concentration range at $2 \mathrm{~h}$ and $6 \mathrm{~h}$ after administration of rifampicin. This results indicate that the treatment had failed because of several factors and one of them is drugs resistance. It can be concluded that the regiment need dose adjustment. Four patients had rifampicin concentration at $2 \mathrm{~h}$ after administration in therapeutic range, but had rifampicin concentration below therapeutic range at $6 \mathrm{~h}$ after administration of rifampicin. It showed that this group of patients had abnormalities in GIT absorption (malabsorption) and drugs interaction. One patient had rifampicin concentration below therapeutic range at $2 \mathrm{~h}$ after administration and had rifampicin concentration at the therapeutic range at $6 \mathrm{~h}$ after administration. Moreover, 3 patients had lower concentration at $2 \mathrm{~h}$ after administration than $6 \mathrm{~h}$ after administration. This results indicates a delayed absorption. $^{7}$

Table 3 showed the correlation of rifampicin dose with its concentration in plasma. This concentration difference may be caused by the difference of rifampicin dose. However, the result showed that there was no guaranteed a higher dose of rifampicin will give high concentration in plasma. In general, patients had $450 \mathrm{mg}$ of rifampicin dosage and 38-54 $\mathrm{kg}$ weight range.

In previous research conducted by $\mathrm{Vu}$ et $\mathrm{al}$, in the determination of rifampicin in plasma and dried blood spot has been compared and had

\begin{tabular}{|c|c|c|c|c|c|c|c|c|}
\hline \multirow[b]{2}{*}{$\begin{array}{l}\text { Concentration } \\
(\mu \mathrm{g} / \mathrm{mL})\end{array}$} & \multicolumn{2}{|c|}{ Area $(\mu \mathrm{V} . s)$} & \multirow[b]{2}{*}{ PAR } & \multicolumn{5}{|c|}{ Measured value } \\
\hline & Rifampicin & IS & & $\begin{array}{c}\text { Concentration } \\
(\mu \mathrm{g} / \mathrm{mL})\end{array}$ & $\begin{array}{c}\text { Average }(\mu \mathrm{g} / \\
\mathrm{mL})\end{array}$ & SD & $\% \mathrm{CV}$ & \% Diff \\
\hline \multirow[t]{5}{*}{1.00} & 2511 & 197729 & 0.0127 & 1.11 & 1.12 & 0.05 & 4.77 & 10.75 \\
\hline & 2629 & 189975 & 0.0138 & 1.19 & & & & 19.27 \\
\hline & 2882 & 216994 & 0.0133 & 1.15 & & & & 15.10 \\
\hline & 2578 & 200448 & 0.0129 & 1.12 & & & & 11.96 \\
\hline & 2806 & 235730 & 0.0119 & 1.05 & & & & 4.80 \\
\hline \multirow[t]{5}{*}{3.00} & 9823 & 252497 & 0.0389 & 3.07 & 3.02 & 0.28 & 9.42 & 2.16 \\
\hline & 8802 & 258832 & 0.0340 & 2.70 & & & & -9.78 \\
\hline & 8582 & 247645 & 0.0347 & 2.75 & & & & -8.20 \\
\hline & 8599 & 208382 & 0.0413 & 3.24 & & & & 7.92 \\
\hline & 9357 & 220590 & 0.0424 & 3.33 & & & & 10.73 \\
\hline \multirow[t]{5}{*}{12.75} & 37033 & 249218 & 0.1486 & 11.27 & 11.63 & 0.57 & 4.92 & -11.64 \\
\hline & 32200 & 221438 & 0.1454 & 11.03 & & & & -13.51 \\
\hline & 36056 & 238991 & 0.1509 & 11.44 & & & & -10.31 \\
\hline & 31142 & 189689 & 0.1642 & 12.43 & & & & -2.51 \\
\hline & 31383 & 198150 & 0.1584 & 12.00 & & & & -5.90 \\
\hline \multirow[t]{5}{*}{22.5} & 59555 & 216782 & 0.2747 & 20.69 & 22.77 & 2.13 & 9.35 & -8.03 \\
\hline & 58438 & 214126 & 0.2729 & 20.56 & & & & -8.63 \\
\hline & 54603 & 161882 & 0.3373 & 25.37 & & & & 12.76 \\
\hline & 53583 & 175101 & 0.3060 & 2303 & & & & 2.37 \\
\hline & 55229 & 171611 & 0.3218 & 24.21 & & & & 7.62 \\
\hline
\end{tabular}




\begin{tabular}{|c|c|c|c|c|c|c|c|c|c|}
\hline \multirow{2}{*}{$\begin{array}{c}\text { LLOQ } \\
\begin{array}{c}\text { Concentration } \\
(\mu \mathrm{g} / \mathrm{mL})\end{array}\end{array}$} & \multirow[b]{2}{*}{ Day } & \multirow[b]{2}{*}{$\begin{array}{l}\text { Concentration } \\
(\mu \mathrm{g} / \mathrm{mL})\end{array}$} & \multicolumn{3}{|c|}{ Within-run } & \multirow[b]{2}{*}{$\%$ Diff } & \multicolumn{3}{|c|}{ Between-run } \\
\hline & & & $\begin{array}{c}\text { Mean } \\
(\mu \mathrm{g} / \mathrm{mL})\end{array}$ & SD & $\%$ CV & & $\begin{array}{c}\text { Mean } \\
(\mu \mathrm{g} / \mathrm{m} \mathrm{L})\end{array}$ & SD & $\% \mathrm{CV}$ \\
\hline & 1 & 1.03 & & & & 3.44 & & & \\
\hline & & 0.97 & & & & -3.03 & & & \\
\hline & & 0.82 & 0.96 & 0.08 & 8.36 & -17.88 & & & \\
\hline & & 0.98 & & & & -2.38 & & & \\
\hline & & 0.98 & & & & -1.74 & & & \\
\hline & 2 & 1.08 & & & & 8.02 & & & \\
\hline & & 0.87 & & & & -13.01 & & & \\
\hline \multirow[t]{8}{*}{1.00} & & 1.16 & 1.03 & 0.11 & 10.74 & 15.61 & 1.01 & 0.12 & 11.40 \\
\hline & & 1.07 & & & & 6.70 & & & \\
\hline & & 0.97 & & & & -2.84 & & & \\
\hline & 3 & 1.19 & & & & 19.37 & & & \\
\hline & & 1.14 & & & & 13.90 & & & \\
\hline & & 0.90 & 1.04 & 0.15 & 14.38 & -10.16 & & & \\
\hline & & 1.12 & & & & 11.53 & & & \\
\hline & & 0.86 & & & & -13.52 & & & \\
\hline
\end{tabular}

a linear concentration of $r=0.95$. Hence, there is no significant difference in determining rifampicin in plasma and dried blood spot and it did not need conversion factors to convert rifampicin concentration in dried blood spot to plasma. ${ }^{13}$ Therefore, bio sampling method with dried blood spot give more advantages compared to plasma for therapeutic drug monitoring because it is less invasive, only small volume needed, a relatively stable analyte, easy in distribution and storage, no phlebotomist needed, reduce the risk of infection and cost-effective.

\section{CONCLUSION}

The analytical method of dried blood spot was linear at concentration range of $1-30 \mu \mathrm{g} / \mathrm{mL}$ and the level of rifampicin in 18 of tuberculosis patients was in the range of 1.26 to $18.33 \mu \mathrm{g} / \mathrm{ml}$. Based on the result, the concentration of rifampicin in patients were varied, there were 7 of 18 patients had concentration in therapeutic range, which shows that the treatment is appropriate. While 11 of 18 patients had concentration below the therapeutic range, which shows that dosage adjustment is needed.

\section{ACKNOWLEDGMENT}

1. Bekasi General Hospital which provides the tuberculosis patients

2. Directorate of Research and Community Services Universitas Indonesia who gives grants for this research.

\section{CONFLICT OF INTEREST}

No conflict of interest is declared.

\section{REFERENCES}

3. Di Piro JT, et al. Pharmacotherapy. A Pathophysiologic Approach, $7^{\text {th }}$ ed. United States of America: McGraw-Hill. 2008

4. World Health Organization. Global Tuberculosis Report. 2016

5. AK H, Kementrian Kesehatan RI. National Guidance in Controlling Tuberculosis. Jakarta: Kementrian Kesehatan RI. 2014

6. Bennett PN, Brown MJ, Sharma P. Clinical Pharmacology 11th edition. UK: Churchill Livingstone. 2012.

7. Neal M. Medical pharmacology at a glance. Chichester, UK: Wiley-Blackwell. 2005;5:15.

8. Brunton L, Parker K, Blumenthal D, Buxton L. Goodman and Gilman's :Manual of Pharmacology and Therapeutics. United States of America: McGraw-Hill Companies. 2008.

9. Peloquin C. Therapeutic Drug Monitoring in the Treatment of Tuberculosis Drugs. 2002.62(15):2169-83

10. Sotgiu G, Alffenaar J, Centis R, D'Ambrosio L, Spanevello A, Piana A, Migliori G Therapeutic drug monitoring: how to improve drug dosage and patient safety in tuberculosis treatment. Intl J Infect Dis. 2015;32:101-4

11. Wilhelm AJ, Jeroen CG, Burger D, Eleonora LS. Therapeutic Drug Monitoring by Dried Blood Spot: Progress to Date and Future Directions. Clin. Pharmacokinet. 2014;53(11):961-73

12. European Medicines Agency. Guideline on Bioanalytical Method Validation London: An agency of the European Union. 2011;44.

13. Fahimi F, Tabarsi P, Kobarfard F, Bozorg B, Goodarzi A, Dastan F, et al. Isoniazid, rifampicin and pyrazinamide plasma concentrations 2 and $6 \mathrm{~h}$ post dose in patients with pulmonary tuberculosis. The Intl $\mathrm{J}$ Tuberc And Lung Dis. 2013;17(12):1602-6.

14. Unsalan S, Sancar M, Bekce B, Clark P, Karagoz T, Izzettin F, et al. Therapeutic Monitoring of Isoniazid, Pyrazinamide and Rifampicin in Tuberculosis Patients Using LC. Chromatographia. 2005;61(11-12):595-8.

15. Vu D, Koster R, Bolhuis M, Greijdanus B, Altena R, Nguyen D, et al. Simultaneous determination of rifampicin, clarithromycin and their metabolites in dried blood spots using LC-MS/MS. Talanta, 2014;121:9-17.

Article History: Submission Date : 11-08-2017 ; Revised Date : 30-09-2017; Acceptance Date : 04-11-2017.

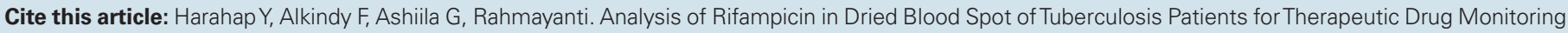
using High Performance Liquid Chromatography. J Young Pharm. 2018;10(1):48-51. 